\title{
Implementation of Crumb Rubber Modified Binder for Qatar Local Roads Construction Projects
}

\author{
Charles N. Nunoo \\ Charles.Nunoo@wsp.com \\ WSP International / Public Works Authority (Ashghal), Roads Projects Department, Doha, Qatar \\ Saoud Ali Al-Tamimi \\ stamimi@ashghal.gov.qa \\ Public Works Authority (Ashghal), Roads Projects Department, Doha, Qatar
}

\begin{abstract}
The continuous increase in the pile up of used vehicle tires in Qatar poses a challenge contributing to potential environmental pollution problems. The magnitude of this problem can be drastically reduced by processing and recycling these tire wastes into crumb rubber, obtained from grinding up whole scrap tires, and incorporating into conventional asphalt binder to produce Crumb Rubber Modified Binder (CRMB) for asphalt mixes used in pavement construction. Asphalt mixtures which incorporates crumb rubber have been used in different parts of the world, notably USA since the 1960s, ostensibly to solve the associated environmental problems, but with added advantages of improving the overall performance of the asphalt pavement in terms of rutting and crack resistance, increased flexibility and durability. In 2018, the Roads Project Department (RPD) in collaboration with the Quality and Safety Department (QSD) of the Public Works Authority (PWA) in Qatar, undertook a demonstration project which utilized CRMB in the wearing course, in lieu of Polymer Modified Binder (PMB) originally proposed. Preliminary results from this project showed an encouraging prospect for adopting Crumb Rubber Modified Binder technology on local road projects, and eventually on all other roads in Qatar. Consequently, it became imperative for a tentative specification to be quickly put together for use by suppliers and contractors to achieve this goal. The preliminary results of this demonstration project are promising and the ensuing crumb rubber and CRMB guidelines have been useful.
\end{abstract}

Keywords: Crumb rubber; Crumb rubber modified binder; Polymer modified bitumen; Asphalt mixtures design; Performance test; Environmental pollution

\section{INTRODUCTION}

Since the 1960s, asphalt mixtures produced with crumb rubber have been used in different parts of the world, notably United States, Canada and many parts of Europe, as a solution for different pavement quality problems and, in the majority of the case, they have demonstrated excellent results by enhancing the overall performance of asphalt pavements. It is well known that the unmodified bitumen has a limited range of rheological properties and durability that are not sufficient to resist pavement distresses, particularly rutting. It has been well-documented around the world including (Harvey et al., 2001) that pavements constructed with CRMB asphalt have demonstrated performance benefits including improved rutting resistance at high temperatures, cracking resistance at low 
temperatures and improved durability, as well as functional benefits such as pavement noise reduction. According to Larsen et al. (1988), the bitumen modification provides binders with sufficient increase in consistency at the highest temperature in pavements to prevent plastic deformation, an increase in flexibility and elasticity of binders to avoid crack deformations and loss of aggregates, improvement of bitumen-aggregate adhesion, improved homogeneity, high thermal stability, and aging resistance which helps reduce the hardening and initial aging of the binders during mixing and construction.

Norhidayah et al. (2019) also demonstrated that CRMB asphalt mixtures provide improved temperature susceptibility and flexibility. The modification is achieved by the interaction of crumb rubber (CR) with the conventional asphalt binder at elevated temperatures for a certain period of time. CRMB asphalt mixtures have several advantages over conventional asphalt mixtures including lower susceptibility to varying temperature on a daily basis, more resistance to deformation at higher pavement temperature, proven aging resistance properties, higher fatigue life for mixes, and better adhesion between aggregate and binder. Evidently, CRMB is a proven technology with sound engineering benefits that has been used to build longer lasting, lower maintenance pavements in a cost-effective manner. The main advantages of this technology include its ability to greatly improve the overall performance of the pavement providing increased fatigue resistance, increased flexibility and durability of the pavement, reduction of pavement noise generated into the local residence, and most importantly, increased cost-effectiveness by lowering overall life-cycle cost, and finally reduction of the accumulation of old vehicle tire debris placed at dump sites, thereby eliminating the otherwise nuisance it poses to the environment.

\section{MAGNITUDE OF THE PROBLEM IN QATAR}

Scrap vehicle tires are being generated and accumulated in large volumes in Qatar causing an increasing threat as a source of environmental pollution. The inappropriate disposal of these tires exacerbates the problems in the immediate and foreseeable future. According to the Qatar Statistics Authority (QSA), at least 500,000 tires are discarded as scrap every year. With the effective age of new tires being about three years in Qatar, the trend is expected to rise. Ironically, though, until recently, there has not been much focus on recycling of used tires in Qatar, which raises more environmental concerns.

In order to eliminate the negative effect of these depositions, in terms of sustainable development, there has been a great interest in processing and recycling these scrap tire wastes into crumb rubber (CR) for incorporation into conventional asphalt binder (60/70 penetration) to produce Crumb Rubber Modified Binder (CRMB), which can then be used for asphalt concrete mixes for pavement construction, as practiced in other countries around the world. With the numerous well documented benefits of crumb rubber for increased fatigue resistance and reduction in ageing of the binder and improving the overall performance of conventional asphalt paving mixes, and in an attempt to mitigate and assuage used vehicle tire menace in Qatar, a concerted effort was taken by PWA and the Ministry of Municipality and Environment to develop a strategy that will encourage the recycling of this scrap tires into road construction, using the existing already proven technologies. 


\section{CRMB IMPLEMENTATION INITIATIVE FOR PWA ROAD PROJECTS}

In line with PWA's strategic objectives for sustainability and preserving the environment, the Roads Projects Department (RPD), in conjunction with WSP International (WSP), undertook an initiative in 2018 to encourage the utilization of crumb rubber as a modifier for asphalt mixes for pavement construction. Accordingly, Nunoo et. al. (2018) submitted a proposal to PWA for the development of a strategy for implementation of this initiative for Qatar local road projects. The proposal was hinged on the aforementioned environmental problem in Qatar and the numerous proven benefits of recycling scrap tires it into asphalt paving mixes for road construction. The objectives established in the proposal included the following:

- Determination of the feasibility of utilizing crumb rubber as modifier for asphalt pavement mixes.

- Ascertaining the cost and benefit of using crumb rubber modified bitumen in lieu of conventional bitumen $(60 / 70)$ or polymer modified bitumen in asphalt pavements construction.

- Determination of the short-term performance of RPD road projects utilizing CRMB asphalt mixes.

- Collection of useful information and data to facilitate the development of a customized CRMB specifications and guidelines for producers and contractors in Qatar.

To achieve these objectives, the following main tasks were identified:

- Establishment of a preliminary specification for implementing a demonstration project.

- Identification of feasible RPD projects for implementing a demonstration project.

- Identification of CR and CRMB suppliers satisfying the preliminary specification.

- Identification of appropriate contactors with capabilities and expertise to implement CRMB.

- Updating of the contract documents to accommodate the selected demonstration projects.

- Implementation of the pilot projects by selected contractors.

- Monitoring of the pilot projects by QSD, a third-party consultant or institution.

- Production of a final report on the performance and lessons learned.

- Development of specification for widespread utilization of CRMB in Qatar.

\section{DEMONSTRATION PROJECT DEVELOPMENT}

After several discussions and coordination, the proposal received a positive response and final approval from PWA. Viable local roads projects were identified to serve as demonstration projects with the main objective of evaluating the constructability and short-term field performance of asphalt concrete mixtures containing crumb rubber.

Subsequent to the approval of this initiative, an initial instruction was issued by the president of PWA for CRMB to be use in lieu of PMB on all projects. It became apparent that there was a need for a quick turnaround to develop a tentative specification and procedures for use by $\mathrm{CR}$ producers and contractors. A number of discussions were held with representatives from PWA Quality and Safety Department (QSD), about the 
best approach for the implementation of the demonstration project in the absence of specification. It was agreed that the implementation should be limited to local roads and in the asphalt wearing course layer. It was also agreed that the demonstration project can use the same mix design as originally developed for the project using PMB. This was based on the consideration that improvement in the properties of these mixtures has been identified as desirable in previous temporary projects in Qatar, including Al Kassarat Street \# 1 in the Industrial Area in 2012, and Al Meena Street project in 2013. Unfortunately, these pavements have been reconstructed at various times and so are not available for evaluation and/or verification.

\section{DEMONSTRATION PROJECT IMPLEMENTATION}

After careful considerations and evaluation of the RPD projects which are scheduled for construction and on the verge of asphalt laying, the Al Kassarat Street \# 2 (DS001Package 2) in the Doha Industrial Area was identified as feasible for the implementation of the demonstration project. This is a six-lane dual carriage roadway with three lanes in each direction. The pavement was designed to accommodate a 20 years design traffic of over 20 million ESALs, and is comprised of $50 \mathrm{~mm}$ of dense graded Wearing Course (19 $\mathrm{mm}$ nominal maximum aggregate size), over a $70 \mathrm{~mm}$ of dense graded Intermediated Course (Base Course Class B), over a $100 \mathrm{~mm}$ of dense graded Base Course, over $200 \mathrm{~mm}$ of granular Subbase Course, over the prepared Subgrade. The uniqueness of this selection is that, the approximately 1-kilometre length of this project had already been constructed up to the intermediate course, in both directions. One direction of the carriageway had already been paved with PMB asphalt mix wearing course. This unique characteristic of the selected project enabled a better assessment of the success of the demonstration project implementation by comparing results of volumetric and performance tests conducted on cores taken from both the PMB and the CRMB sections in both directions.

A coordinated and collaborative effort was undertaken by WSP with the CR supplier (Al Holdaifi), the CRMB supplier (RAETEX Doha), the selected demonstration project's main contractor (QTCG) and the sub-contractor for the paving works (BOOM Construction). An action plan was developed, with support from QSD for the implementation. This was to ensure that the best possible operational conditions for production, construction, evaluation and material testing were ensured. The CRMB used was produced by the supplier in accordance with the pending version of the revised Qatar Construction Standards (QCS, 2018) and complied with a PG76-10H grade. Meanwhile, the adjacent already constructed PMB Wearing Course segment, in the opposite direction, complied with a PG76-10E grade. It is to be noted that the support for implementation of this demonstration project, by the suppliers and contractors, was undertaken at no additional cost to PWA, as a goodwill gesture to enable this important initiative to materialize.

\section{PRELIMINARY TEST RESULTS FROM DEMONSTRATION OF PROJECT}

During construction, extra sampling on-site as well as from the plant were collected and specialized tests were performed by QSD, in addition to the standard quality control and quality assurance tests. The preliminary report indicated the following observations: 
- The mix design was considered inadequate and asphalt mixture aggregates were not controlled to optimize packing.

- Both the PMB and the CRMB segments did not meet the air voids requirements, probably as a result of the inadequate mix design and/or the level of compaction employed, as it was observed that the steel. breakdown rolling was only two passes and pneumatic tire rolling was prolonged.

- Some level of segregation was observed at the edges of runs, probably due to paver adjustment.

- The mix arrived at a reasonable paving temperature and did not overly smoke but there was some little odor coming from the asphalt fumes.

- All other volumetric properties were in conformance with (QCS, 2014) requirements. Preliminary performance tests on cores undertaken, including Dynamic Modulus, Flow Number, 4-Point Fatigue Test, Resilient Modulus, Flexural Modulus and Overall Stiffness, to determine the performance comparability of CRMB asphalt with the adjacent PMB asphalt segment. The outcome from the performance test indicated the following characteristics:

- Since the original PMB Marshall design was based on a different aggregate gradation from what was used for the CRMB mix, the Marshall stiffness, stability and flow are considered to be of limited value, even though, they appeared to be in compliance with Qatar Construction Standards (QCS, 2014).

- The performance data showed that the CRMB mix has higher dynamic modulus and higher overall stiffness in all modes of measurement, and therefore very good resistance to deformation and fatigue.

- The CRMB mix also had lower phase angle and hence higher contribution of elastic modulus to the complex modulus, which means better low temperature properties and crack resistance.

- CRMB mixes would potentially have comparable or even better performance than the PMB mixes.

- Results are consistent with international, particularly terminal blend experience from the USA.

It was concluded from the preliminary results, particularly the high in-place air void, that further work is required to improve the mix design by making it essentially performance-based. It was obvious from the results that there was a need for the development of a comprehensive guidelines for asphalt mixtures containing CRMB. To this end, a concerted collaborative effort was quickly set in place to undertake a second demonstration project with a performance-based mix design developed from contributions by QSD, BOOM construction, RAETEX Doha and FUGRO laboratories. The first trial of the initial mix design produced from this effort was implemented on an ongoing paving project. Preliminary results from cores taken after paving showed that the mix design needed to be improved to address some concerns with volumetric properties. However, due to some logistics and other challenges this effort was suspended.

\section{DEVELOPMENT OF CR AND CRMB SPECIFICATIONS FOR QATAR}

Following the successful implementation of the first demonstration project in 2018, and the second uncompleted attempt to improve on the results of the first, it became 
imperative that a new specification needed to be developed or the existing specification revised before attempting to adopt and utilize in a conventional production basis. Accordingly, the QSD took the initiative to compile and issued a tentative guideline for the pre-qualification of CR and CRMB producers together with a guideline for Mix Design and Quality Control of CRMB asphalt mixes. These guidelines were prepared in line with the existing (QCS, 2014) and the pending (QCS, 2018). Essentially, the specifications in the guidelines control CR usage in CRMB production for utilization in a variety of asphalt paving applications. However, the specification does not address any safety or environmental concerns associated with its use. The salient points inherent in these two guidelines and specifications release in 2018 are presented in the next sections.

\subsection{Requirements for Prequalification CR and CRMB Producers}

The guideline details the requirements for pre-qualification of producers engaged in the production of CR and CRMB for PWA pavement construction projects. The producers' quality management system, general plant information, technical details and quality control plan should be submitted to the PWA Quality and Safety Department to express their desire for pre-qualification.

\section{Crumb Rubber Producers Pre-qualification Requirements}

a) The crumb rubber should be derived from car and/or truck tires and should be sufficiently free from contaminants including fabric, metal mineral and other nonrubber substances.

b) When tested in accordance with ASTM D5644 (selected sieves: 30-mesh, 40-mesh, 80-mesh, 200-mesh and 400-mesh), the resulting crumb rubber gradation should be 30 mesh (600 microns) type.

c) When tested in accordance with ASTM D1864, the crumb rubber should contain no more than $0.75 \%$ moisture by weight and should be free flowing with oven temperature equal to $105 \pm 5^{\circ} \mathrm{C}$.

d) Specific gravity of the rubber should be $1.15 \pm 0.05$, as determined by BS EN 10977 , making use of a suitable liquid in which the crumb rubber will not dissolve or react (e.g. ethyl alcohol).

e) The crumb rubber should not contain visible nonferrous metal particles and not more than $0.01 \%$ ferrous metal particles by weight. Metal particles should be detected and separated by thoroughly stirring a magnet through a $50 \mathrm{~g}$ sample and weighing the captured particles. Nonferrous metal particles should be detected by visual inspection.

f) The crumb rubber should contain no more than $0.1 \%$ fiber by weight. Method of determining fiber content should be specified by the CR supplier to the CRMB producer.

g) The crumb rubber should contain less than $0.25 \%$ foreign contaminant materials (e.g. glass, sand, wood) by weight.

h) Crumb rubber sampling should be conducted from approximately 1-ton quantity in accordance with "California State Transportation Agency - California Test 385 (Section D) dated December 2015" with minimum testing frequency for quality control every 15 tons of production. 


\section{Crumb Rubber Modified Binder Producers Pre-qualification Requirements}

a) When tested in accordance with ASTM D5546 or AASHTO T44, used to verify the residue of a CRMB placed in an ignition oven or furnace at $400^{\circ} \mathrm{C}$ for 1 hour, the binder should not contain fibers or discrete particles other than rubber with longest dimensions greater than $250 \mu \mathrm{m}$.

b) The binder should be graded in accordance with AASHTO M332. However, the solubility test, binder stress sensitivity test and viscosity requirements are waived. The test should be carried out as per AASHTO T315 and T350 and performed with $2 \mathrm{~mm}$ gap.

c) The CRMB producer should provide a certificate that indicates the supplier of the $\mathrm{CR}$, type and percentage of CR and any other additives (percentages of CR allowed in the CRMB should be between $10 \%$ to $25 \%$ by weight) and quality control test results issued by an approved independent third-party laboratory.

d) CRMB producers should provide guidelines to contractors for transportation; storage and handling of their binders (e.g. need for storage in continuously agitated tanks at the modification terminal and the asphalt plant). Recommendations for asphalt mixing and compaction temperature ranges should clearly be specified.

\subsection{Requirements for CRMB Asphalt Mix Design Certification}

In order for a contractor to obtain asphalt mix design conformity certificate for the production of asphalt for PWA road projects, the following requirements, among others, must be adhered to:

- PG76-10 binders grade to be used in asphalt mixes in accordance with AASHTO M332, with necessary adjustments to account for traffic loading and speed.

- Optionally, the contractor may use the Marshall or Superpave mix design methodology for the asphalt mix design. Albeit, most contractors in Qatar typically use only the Marshall method for their designs.

Table 1: Design Criteria for Marshall CRMB Mix Design

\begin{tabular}{|c|c|c|c|}
\hline Parameter $^{1}$ & $\mathbf{B C}-\mathbf{A}$ & $\mathbf{B C}-\mathbf{B}$ & WC \\
\hline Aggregate Properties & \multicolumn{3}{|c|}{ Tables 5.1 and $5.2(\mathrm{QCS} 2014)$} \\
\hline Aggregate Grading & \multicolumn{3}{|c|}{ Table 5.7 (QCS2014) } \\
\hline Number of Compaction blows at each end of specimen & 75 & 75 & 75 \\
\hline Binder Content ( $\%$ of total mix) inclusive of tolerances & $3.2-4.4$ & $3.4-4.4$ & $3.4-4.4$ \\
\hline Stability $(\mathrm{kN})$ & $12.0 \mathrm{~min}$. & $12.0 \mathrm{~min}$. & $13.0 \mathrm{~min}$. \\
\hline Flow (mm) & $2-4$ & $2-4$ & $2-4$ \\
\hline Marshall Quotient (Stability/Flow) $(\mathrm{kN} / \mathrm{mm})$ & $5.25 \mathrm{~min}$. & $5.25 \mathrm{~min}$. & $5.25 \mathrm{~min}$. \\
\hline Voids in Mix (Air Voids) (\%) & $4-8$ & $4.5-8$ & $5-8$ \\
\hline Voids in Mineral Aggregate VMA (\%) & \multicolumn{3}{|c|}{ Table 5.9 (QCS2014) } \\
\hline Voids Filled with Asphalt VFA (\%) & $50-70$ & $50-75$ & $50-75$ \\
\hline $\begin{array}{l}\text { Voids in Marshall Specimen at } 400 \text { Blows per face at } \\
\text { optimum binder content }(\%)\end{array}$ & $3.2 \mathrm{~min}$. & $3.4 \mathrm{~min}$. & $4.0 \mathrm{~min}$. \\
\hline Retained Stability (\%) & $75 \mathrm{~min}$. & $75 \mathrm{~min}$. & $75 \mathrm{~min}$. \\
\hline Filler/Binder Ratio & $0.80-1.50$ & $0.80-1.50$ & $0.75-1.35$ \\
\hline Tensile Strength Ratio at $25^{\circ} \mathrm{C}$, ASTM D4867 (\%) & $75 \mathrm{~min}$ & $75 \mathrm{~min}$ & $75 \mathrm{~min}$ \\
\hline $\begin{array}{l}\text { Rut depth using HWTT }{ }^{2} \text { at } 60^{\circ} \mathrm{C} \text {, Wet, } 20,000 \text { passes, } \\
\text { AASHTO T324 (mm) }\end{array}$ & $12.5 \max$. & $12.5 \max$. & $12.5 \max$. \\
\hline
\end{tabular}

Note:- ${ }^{1}$ Unless otherwise stated, relevant ASTM standards shall be followed for testing. 


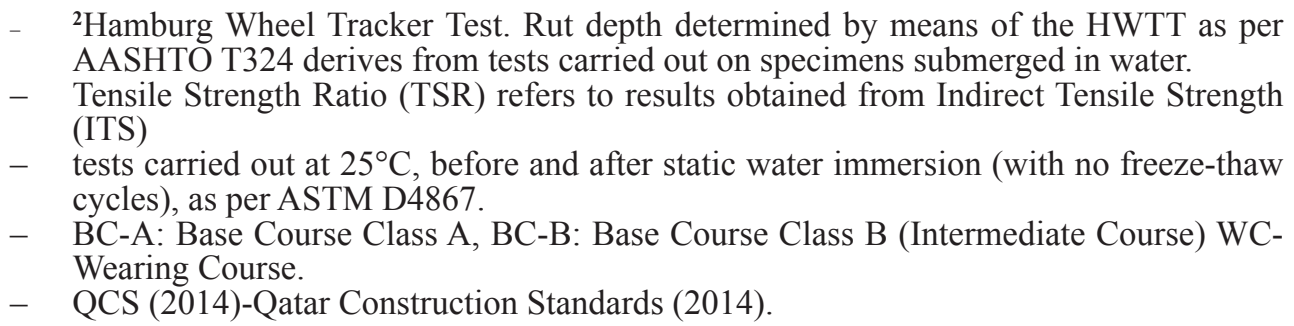

\section{IMPLEMENTATION OF CRMB ON PWA PROJECTS}

In addition to the initial instruction by the PWA president for CRMB to be use in lieu of PMB for all projects, the Roads Projects Department also issued an instruction for CRMB to be used in lieu of the conventional 60/70 bitumen for the Wearing Course mixes for all projects. As a result, the local $\mathrm{CR}$ and $\mathrm{CRMB}$ producers and contractors engaged in a concerted effort and work collaboratively to acquire the necessary certification and mix design approvals from QSD, based on the guidelines and specifications provided. Currently, two approved local CRMB producers, namely RAETEX Doha and MEMBCO, who obtains their CR from approved local suppliers (Al Holdaifi Recycling Qatar and Bright Future Tire Recycling) have been approved to supply contractors with the required CRMB for their asphalt mixes. The main challenges that the contractors have faced in the development of their asphalt mix designs have to do with the difficulty in satisfying the minimum $75 \%$ tensile strength ratio (TSR) requirement shown Table 1 . The other challenge has to do with the strong odors that emanate from the asphalt fumes. That notwithstanding, in the last couple of months several contractors, in close co-operation with their respective CRMB producers, have managed to overcome these challenges and develop compliant $\mathrm{CRMB}$ asphalt mixes and obtained the required conformity certificates for the production of asphalt mixtures for their respective projects.

In September 2019 the initiative achieved a major milestone as the first CRMB Wearing Course meeting all applicable specifications was successfully implemented on Roads and Infrastructure in North of Al Nasiraiyah RPD project, by BOOM Construction Co. \& Lotus Trading \& Contracting Co. JV, after a successful plant trial. Many more contractors are expected to be laying CRMB asphalt mixes on several RPD projects in the coming months. Preliminary results show that all Marshall properties, such as air voids, voids in the mineral aggregate (VMA), and voids filled with asphalt (VFA) have been conformed to, for both the loose and compacted mixes. Particularly, air voids between $5.5 \%$ to $7.5 \%$ have been achieved on two projects executed so far, compared to the high percentages achieved for the demonstration project. Temperature regimes are in the region of $170^{\circ} \mathrm{C}$ to $178^{\circ} \mathrm{C}$ at the plant, $165^{\circ} \mathrm{C}$ to $170^{\circ} \mathrm{C}$ in truck at site, $160^{\circ} \mathrm{C}$ to $165^{\circ} \mathrm{C}$ laying temperatures and breakdown rolling carried out between $165^{\circ} \mathrm{C}$. These results are considered very promising.

The PWA (RPD and QSD) will be closely monitoring the implementations of these mixes to ensure that all applicable quality standards and specification are strictly adhered to in order to guarantee the expected short- and long-term performance.

\section{CONCLUSION AND RECOMMENDATIONS}

The benefits of using CRMB are well documented worldwide with the major driver 
for its implementation in Qatar, besides increased fatigue resistance and reduction in ageing of the binder, being the environmental pollution reduction benefits. Currently, the use of CRMB for the Wearing Course is mandated in Qatar for local roads projects and recommended as a substitute for other projects where PMB has been specified. This is considered a major shift in paradigm and considered a very bold initiative by PWA. Even though it is estimated that there is cost impact of using CRMB over conventional $60 / 70$ binders, it is anticipated that the overall benefits and lower lifecycle cost will far outweigh the additional cost impact. It is of paramount importance, though, that the implemented projects be monitored and evaluated diligently by collecting useful information and data that will help in developing a more customized specifications for CRMB producers and contractors in Qatar. To this end, the following recommendations are made by the authors:

1. PWA should develop a strategy to involve other institutions such as Qatar University and Texas A\&M University in Qatar to undertake targeted funded research to develop improved mix designs which are essentially performance-based.

2. The long-term performance of these mixes should be monitored annually by a systematic approach to performance testing including the evaluation of the rutting resistance, cracking resistance, and moisture susceptibility of the asphalt mixtures on different segments with various pavement designs and having varying asphalt mix designs and different crumb rubber components.

3. To boost the environmental pollution reduction benefits aspect of this initiative, the requirement in the guidelines for the crumb rubber content in CRMB to be between $10 \%$ and $25 \%$ by weight must be strictly adhered to and verified prior to issue of conformity certificate.

4. Certification programs should be developed to ensure training of technical personnel of producers, contractors, supervision staff, as well as PWA engineers engaged in the implementation of CRMB.

5. Since current Qatar pavement design is based on the AASHTO empirical design methodology, it will be of immense advantage if the material properties of asphalt mixes with the different grades of CRMB are characterized in terms of their layer coefficient. It is believed that with the expected much higher layer coefficients compared to the conventional asphalt mixes; the pavement designs could be optimized largely which could lead to significant cost savings.

6. Preferably, a performance-based balanced mix design procedure for CRMB asphalt mixtures, which is fast becoming the industry best practice approach, should be evaluated in order to move towards implementation for all asphalt mix designs in Qatar.

\section{ACKNOWLEDGMENTS}

The authors would like to thank the president of PWA, Eng. Dr. Saad Ahmed Ibrahim Al Mohannadi for embracing this initiative and giving it the needed support and approvals. Acknowledgement goes to the following individuals at PWA's Quality and Safety Department (QSD) and ANAS S.p.A Qatar Branch for their immense contributions and support, namely; Eng. Khalid Mohd Al-Emadi (QSD Department Manager), Dr. Osman Elhusain Mohamed Idris (QSD Senior Quality Engineer) and Glyn Holleran (former 
ANAS Pavement Expert). Particular appreciation goes to Naser Al Bash (Sr. ManagerQA/QC for BOOM Construction Company) and Banji Obikunle (QA/QC Technical Manager for RAETEX Doha). The following PWA Roads Projects Department engineers are also recognized for their valuable support and contribution, namely; Eng. Aly Fahmy (RPD Design Manager) and Eng. Mustafa Shireim (RPD Project Manager) and Roger Hodgson (Senior Materials Specialist at PWA Highway Projects Department).

\section{REFERENCES}

Guidelines for Mix Design and Quality Control of CRMB Asphalt Mixes (2018). Published by PWA Quality and Safety Department, Qatar.

Guidelines for Pre-qualification for crumb rubber and crumb rubber modified binder producers (2018). Published by PWA Quality and Safety Department, Qatar.

Harvey, J., Weissman, S., Long, F. \& Monismith, C. (2001). Tests to evaluate the stiffness and permanent deformation characteristics of asphalt/binder-aggregate mixes, and their use in mix design and analysis. Proceedings of the Asphalt Paving Technology, pp. 572-604.

Larsen, J. E., Wohlk, C. J. \& Hall, B. A. (1988). Modified bitumen. Proceedings of the 14th Australian Road Research Board Conference (ARRB '88), Canberra, Australia.

Norhidayah, A. H. et al. (2019). Engineering properties of crumb rubber modified dense graded asphalt mixtures using dry process. IOP Conference Series: Earth and Environmental Science, 220.

Nunoo, C., Fahmy, A. (2018). Utilization of Crumb Rubber for Asphalt Pavement Construction on Local Roads and Drainage Projects in Qatar. Proposal submitted to the Public Works Authority (Ashghal), Qatar. 